\title{
Physical therapy in the management of frozen shoulder
}

\author{
Hui Bin Yvonne $\underline{C h a n}^{1}$, BSc(Hons), Pek Ying $\underline{\text { Pua }}^{2}$, BPhty, MManipPhty, Choon How $\underline{H o w}^{1}$, MMed, FCFP
}

Lucy, a 53-year-old woman, visited you several times in the past year. She had an aching pain on her shoulder and, lately, had increasing difficulty lifting her arm or reaching behind her back. You previously gave her painkillers as treatment. However, due to her history of gastric problems, you were keen to explore physical therapy as part of management.

\section{WHAT IS FROZEN SHOULDER?}

Frozen shoulder, also known as adhesive capsulitis, is defined as "a condition of uncertain aetiology, characterised by significant restriction of both active and passive shoulder motion that occurs in the absence of a known intrinsic shoulder disorder". (1) Patients with frozen shoulder typically experience insidious shoulder stiffness, severe pain that usually worsens at night, and near-complete loss of passive and active external rotation of the shoulder. ${ }^{(2)}$ There are typically no significant findings in the patient's history, clinical examination or radiographic evaluation to explain the loss of motion or pain.

Frozen shoulder can be classified as primary or secondary. Primary idiopathic frozen shoulder is often associated with other diseases and conditions, such as diabetes mellitus, and may be the first presentation of a diabetic patient. ${ }^{(3)}$ Patients with systemic diseases such as thyroid diseases ${ }^{(4,5)}$ and Parkinson's disease ${ }^{(6)}$ are at higher risk. Secondary adhesive capsulitis can occur after shoulder injuries or immobilisation (e.g. rotator cuff tendon tear, subacromial impingement, biceps tenosynovitis and calcific tendonitis). These patients develop pain from the shoulder pathology, leading to reduced movement in that shoulder and thus developing frozen shoulder.

Frozen shoulder often progresses in three stages: the freezing (painful), frozen (adhesive) and thawing phases (Fig. 1). In the freezing stage, which lasts about 2-9 months, there is a gradual onset of diffuse, severe shoulder pain that typically worsens at night. The pain will begin to subside during the frozen stage with a characteristic progressive loss of glenohumeral flexion, abduction, internal rotation and external rotation. This stage can last for 4-12 months. During the thawing stage, the patient experiences a gradual return of range of motion that takes about 5-26 months to complete. ${ }^{(7,8)}$ Although adhesive capsulitis is often self-limiting, usually resolving in $1-3$ years, ${ }^{(9)}$ it can persist, presenting symptoms that are commonly mild; pain is the most common complaint. ${ }^{(10,11)}$

\section{HOW COMMON IS THIS IN MY PRACTICE?}

Frozen shoulder is estimated to affect $2 \%-5 \%$ of the general population, ${ }^{(12)}$ and can be significantly painful and disabling. It most commonly affects those in their fourth to sixth decades of life, and more often occurs in women than in men. ${ }^{(8,13)}$

The term 'frozen shoulder' is often loosely used and wrongly attributed to other shoulder limitations such as a rotator cuff tear or osteoarthritis. Subacromial pathology (e.g. rotator cuff tendinopathy, subacromial bursitis and impingement syndrome) can closely resemble frozen shoulder in the early stages as well. (7) For appropriate management, it is important for physicians to ascertain the diagnosis. As the physical therapy described in this article is specifically targeted at adhesive capsulitis, techniques for other shoulder conditions require further customisation.

\section{WHAT CAN I DO IN MY PRACTICE?}

Most frozen shoulder cases can be managed in the primary care setting. Clinicians are encouraged to start the treatment with patient education. Explaining the natural history of the condition often helps to reduce frustration, increase compliance and allay fears for the patient. It is also advisable to acknowledge that full range of motion may never be restored. Common conservative treatments for frozen shoulder include nonsteroidal antiinflammatory drugs (NSAIDs), glucocorticoids given orally or as intra-articular injections, and/or physical therapy. ${ }^{(14)}$ Many practitioners, however, find themselves limited to prescribing medications to relieve pain and inflammation.

Many physical therapy and home exercises can be used as a first-line treatment for adhesive capsulitis. ${ }^{(12)}$ Physical therapy has been shown to bring about pain relief and return of functional motion. ${ }^{(15)}$ When used in combination with physical therapy, NSAIDs were proven to be more effective as compared to using NSAIDs alone. ${ }^{(16)}$ Similarly, various studies on intra-articular corticosteroids used in combination with physiotherapy resulted in better outcomes compared to intra-articular corticosteroids alone. ${ }^{(17,18)}$ 
Table I. A summary of the three phases of frozen shoulder.

\begin{tabular}{|c|c|c|c|}
\hline & Freezing & Frozen & Thawing \\
\hline Duration & $2-9 \mathrm{mth}$ & $4-12 \mathrm{mth}$ & $5-26 \mathrm{mth}$ \\
\hline Signs and symptoms & $\begin{array}{l}\text { Gradual onset of diffuse, severe } \\
\text { shoulder pain that worsens at night }\end{array}$ & $\begin{array}{l}\text { Pain begins to subside but there is } \\
\text { a characteristic progressive loss of } \\
\text { range in motion }\end{array}$ & $\begin{array}{l}\text { Gradual return of range of } \\
\text { motion }\end{array}$ \\
\hline Conservative treatment & \multicolumn{3}{|c|}{$\begin{array}{l}\text { - Patient education } \\
\text { - Medications: nonsteroidal anti-inflammatory drugs, oral or intra-articular glucocorticoids } \\
\text { - Physical therapy }\end{array}$} \\
\hline $\begin{array}{l}\text { Physical therapy at each } \\
\text { stage }\end{array}$ & $\begin{array}{l}\text { - Gentle stretching exercises } \\
\text { - Modalities: heat/ice pack }\end{array}$ & $\begin{array}{l}\text { - Maintain stretching exercises } \\
\text { - Strengthening exercises: } \\
\text { isometric/static } \\
\text { - Modalities: heat/ice pack }\end{array}$ & $\begin{array}{l}\text { - Maintain stretching } \\
\text { exercises } \\
\text { - Strengthening exercises that } \\
\text { progress from isometric/ } \\
\text { static to resistance-based }\end{array}$ \\
\hline
\end{tabular}

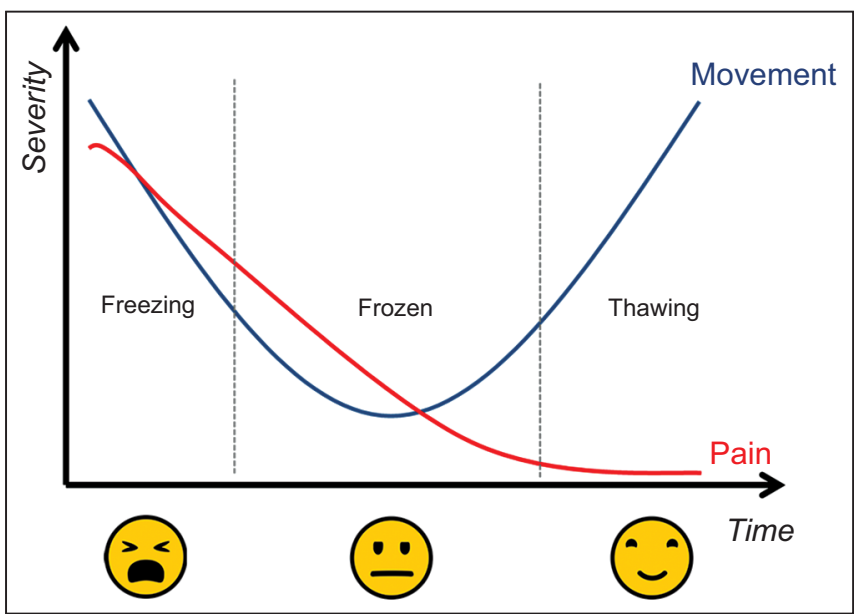

Fig. 1 Chart shows the clinical presentation of frozen shoulder. Icons with facial expressions represent the level of pain of the patient.

The physical therapy for primary idiopathic frozen shoulder described herein can be useful for prescribing home exercises to increase shoulder mobility. Nevertheless, it is imperative to consider the patient's symptoms and stage of the condition when selecting a physical treatment method for frozen shoulder. Table I summarises the key features of each stage.

\section{Freezing phase}

Pain is often most severe during the freezing phase and patients in this phase would benefit from learning pain-relieving techniques. These exercises include gentle shoulder mobilisation exercises within the tolerated range (e.g. pendulum exercise, passive supine forward elevation, passive external rotation, and active assisted range of motion in extension, horizontal adduction, and internal rotation). A heat or ice pack can be applied as a modality to relieve pain before the start of these exercises. The application of moist heat in conjunction with stretching has been shown to improve muscle extensibility. ${ }^{(19)}$ Certain patients might also find it useful to take analgesics before physical therapy.

Patients should begin with short-duration ( $1-5$ seconds) range of motion exercises, which should be in a relatively pain-free range. ${ }^{(20)}$ Fig. 2 shows three commonly performed stretching exercises that are particularly useful for patients in this painful stage. Pendulum exercises can be used in flexion or abduction or circular motion. Patients can also try pulley exercises, as tolerated, and neck or scapular muscle releases. It is important not to aggravate a frozen shoulder, as aggressive stretching beyond the pain threshold can result in inferior outcomes, particularly in the early phase of the condition. ${ }^{(21)}$ There has also been evidence that patients should avoid a forward shoulder posture as it may cause a loss of glenohumeral flexion and abduction. ${ }^{(22)}$

\section{Frozen phase}

Similar to the freezing phase, a heat or ice pack can be applied during the frozen phase to relieve pain before commencing exercises. Home exercises such as those in Fig. 2 can be continued within the tolerated limit. In particular, stretching exercises for the chest muscles and muscles at the back of the shoulder should be maintained. Rotation before elevation exercises, such as an external rotation stretch, are also recommended to avoid increasing pain and inflammation. ${ }^{(22)}$ At this stage, strengthening exercises are added to maintain muscle strength. Isometric or static contractions are exercises that require no joint movement and can be done without worrying about increasing pain in the shoulder.

Fig. 3 shows strengthening exercises that can be performed at home. The scapular retraction exercises gently stretch the chest muscles and serve as basic strengthening for the scapular muscles. Isometric shoulder external rotation can also be used for flexion or abduction, within the available range, but care should still be taken to avoid introducing aggressive exercises, as overenthusiastic treatment could aggravate the capsular synovitis and subsequently cause pain.

\section{Thawing phase}

In the thawing phase, the patient experiences a gradual return of range of motion. It is crucial to get the shoulder back to normal as quickly as possible by regaining full movement and strength. Strengthening exercises are important, as the shoulder is considerably weakened after a few months of little movement. Compared to the frozen phase, the patient can perform more mobility exercises and stretches (e.g. Figs. 2 \& 3) with a longer holding duration, within tolerated boundaries. Strengthening exercises can also progress from isometric or static contractions, to exercises using a resistance band, and eventually to free weights 

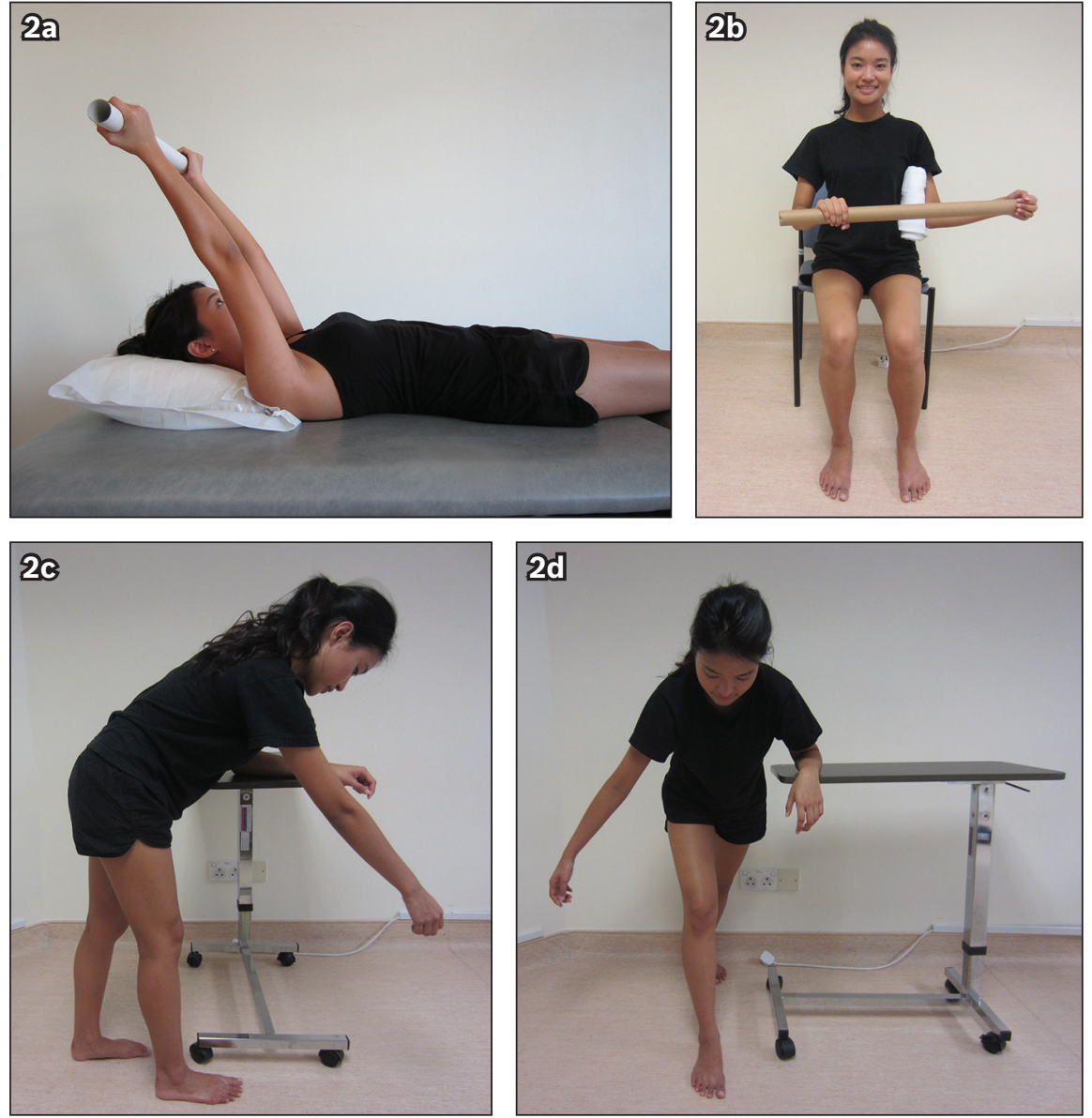

Fig. 2 Photographs show examples of stretching exercises: (a) active assisted shoulder forward flexion with wand; (b) active assisted shoulder external rotation with wand; and $(c \& d)$ pendulum exercise.
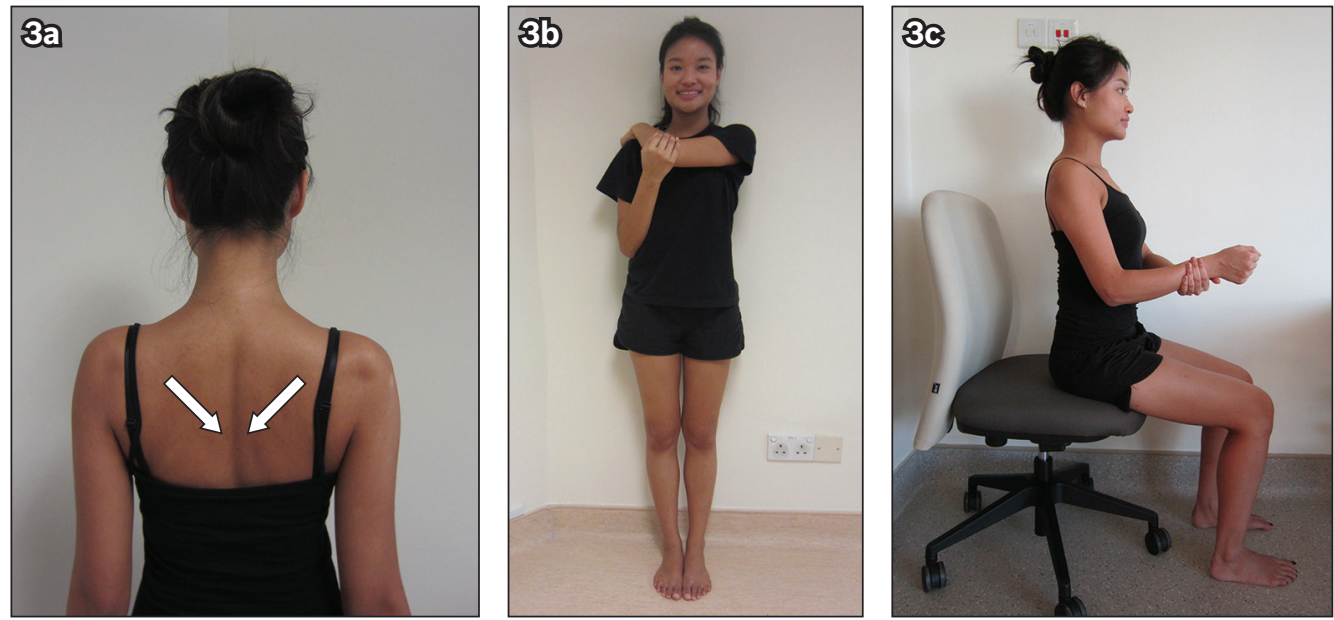

Fig. 3 Photographs show examples of strengthening exercises: (a) scapular retraction; (b) posterior capsule stretch; and (c) isometric shoulder external rotation. In scapular retraction, the scapulae are pulled towards each other (arrows in a).

or weight machines. Rotator cuff exercises, as well as posture exercises and exercises for the deltoid and chest muscles, can be included in the treatment as well.

\section{Referral}

Referral to a physiotherapist can be made when the physician thinks that the patient's condition needs more guidance and can benefit from a physiotherapist review, or when the patient's condition fails to improve after trialling exercises such as the above. Referral to an orthopaedics specialist may be necessary if some investigations are needed, such as radiography of the shoulder (to look for calcific tendonitis or acromial bone spur, i.e. a Type 3 Bigliani spur) and magnetic resonance imaging of the shoulder to rule out cuff tear.

Manipulation of the frozen shoulder under regional anaesthesia together with intra-articular glenohumeral joint 
cortisone injection is an effective form of treatment in frozen shoulder without cuff tear. This is especially so if the patient would like a rapid improvement in symptoms and avoid the expected natural history of pain, stiffness and slow gradual thawing of the stiff shoulder.

Lucy started on strengthening exercises at home, following your instructions. On her next visit to your clinic, she was happy to report that these exercises had relieved some of her pain and improved her shoulder movement. You assured her that her condition usually takes time to recover and instructed her to progress to resistance-based exercises. You noted that she was on track to recovery and did not refer her to a physiotherapist.

ABSTRACT Frozen shoulder, also known as adhesive capsulitis, is a common presentation in the primary care setting and can be significantly painful and disabling. The condition progresses in three stages: freezing (painful), frozen (adhesive) and thawing, and is often self-limiting. Common conservative treatments include nonsteroidal anti-inflammatory drugs, oral glucocorticoids, intraarticular glucocorticoid injections and/or physical therapy. However, many physicians may find themselves limited to prescribing medications for treatment. This article elaborates on physical therapy exercises targeted at adhesive capsulitis, which can be used in combination with common analgesics.

Keywords: adhesive capsulitis, frozen shoulder, physical therapy, self-management

\section{TAKE HOME MESSAGES}

1. Patients with frozen shoulder typically experience insidious shoulder stiffness and near-complete loss of passive and active external rotation of the shoulder.

2. Frozen shoulder occurs in three phases: freezing (painful), frozen (adhesive) and thawing, and is often self-limiting.

3. Common conservative treatments for frozen shoulder include NSAIDs, glucocorticoids given orally or as intraarticular injections, and/or physical therapy.

4. Physical therapy and home exercises can be a first-line treatment for frozen shoulder, with consideration of the patient's symptoms and stage of the condition.

5. In the freezing (painful) stage, gentle stretching exercises can be done but should be kept within a short duration (1-5 seconds) and not go beyond the patient's pain threshold.
6. In the frozen (adhesive) stage, strengthening exercises such as scapular retraction, posterior capsule stretch and isometric shoulder external rotation can be added to the patient's exercises for maintenance of muscle strength.

7. In the thawing stage, the patient experiences a gradual return of range of motion; both stretching and strengthening exercises can increase in intensity, with a longer holding duration.

\section{ACKNOWLEDGEMENT}

Figs. 2 and 3 are reproduced with permission of Changi General Hospital, Singapore.

\section{REFERENCES}

1. Zuckerman JD, Rokito A. Frozen shoulder: a consensus definition. J Shoulder Elbow Surg 2011; 20:322-5.

2. Brue S, Valentin A, Forssblad M, Werner S, Mikkelsen C, Cerulli G. Idiopathic adhesive capsulitis of the shoulder: a review. Knee Surg Sports Traumatol Arthrosc 2007; 15:1048-54

3. Pal B, Anderson J, Dick WC, Griffiths ID. Limitation of joint mobility and shoulder capsulitis in insulin- and non-insulin-dependent diabetes mellitus. $\mathrm{Br}$ I Rheumatol 1986; 25:147-51.

4. Cakir M, Samanci N, Balci N, Balci MK. Musculoskeletal manifestations in patients with thyroid disease. Clin Endocrinol (Oxf) 2003; 59:162-7.

5. Wohlgethan JR. Frozen shoulder in hyperthyroidism. Arthritis Rheum 1987; 30:936-9.

6. Riley D, Lang AE, Blair RD, Birnbaum A, Reid B. Frozen shoulder and other shoulder disturbances in Parkinson's disease. J Neurol Neurosurg Psychiatry 1989; 52:63-6.

7. Prestgaard TA. Frozen shoulder (adhesive capsulitis). In: UpToDate [online]. Available at: https://www.uptodate.com/contents/frozen-shoulder-adhesivecapsulitis. Accessed November 1, 2017.

8. Dias R, Cutts S, Massoud S. Frozen shoulder. BMJ 2005; 331:1453-6.

9. Maund E, Craig D, Suekarran S, et al. Management of frozen shoulder: a systematic review and cost-effectiveness analysis. Health Technol Assess 2012; 16:1-264.

10. Hand C, Clipsham K, Rees JL, Carr AJ. Long-term outcome of frozen shoulder. J Shoulder Elbow Surg 2008; 17:231-6.

11. Vastamäki H, Kettunen J, Vastamäki M. The natural history of idiopathic frozen shoulder: a 2- to 27-year followup study. Clin Orthop Relat Res 2012; 470:1133-43.

12. Hsu JE, Anakwenze OA, Warrender WJ, Abboud JA. Current review of adhesive capsulitis. J Shoulder Elbow Surg 2011; 20:502-14.

13. Rizk TE, Pinals RS. Frozen shoulder. Semin Arthritis Rheum 1982; 11:440-52.

14. Wong PL, Tan HC. A review on frozen shoulder. Singapore Med J 2010; 51:694-7.

15. Page $P$, Labbe A. Adhesive capsulitis: use the evidence to integrate your interventions. N Am J Sports Phys Ther 2010; 5:266-73.

16. Dudkiewicz I, Oran A, Salai M, Palti R, Pritsch M. Idiopathic adhesive capsulitis: long-term results of conservative treatment. Isr Med Assoc J 2004; 6:524-6.

17. Page MJ, Green S, Kramer S, et al. Electrotherapy modalities for adhesive capsulitis (frozen shoulder). Cochrane Database Syst Rev 2014; (10):CD011324.

18. Mobini M, Kashi Z, Bahar A, Yaghubi M. Comparison of corticosteroid injections, physiotherapy, and combination therapy in treatment of frozen shoulder. Pak J Med Sci 2012; 28:648-51.

19. Järvinen TA, Järvinen $T L$, Kääriäinen $M$, Kalimo H, Järvinen M. Muscle injuries: biology and treatment. Am J Sports Med 2005; 33:745-64.

20. Kelley MJ, McClure PW, Leggin BG. Frozen shoulder: evidence and a proposed model guiding rehabilitation. J Orthop Sport Phys Ther 2009; 39:135-48.

21. Diercks RL, Stevens M. Gentle thawing of the frozen shoulder: a prospective study of supervised neglect versus intensive physical therapy in seventy-seven patients with frozen shoulder syndrome followed up for two years. J Shoulder Elbow Surg 2004; 13:499-502.

22. Donatelli R, Ruivo RM, Thurner M, Ibrahim MI. New concepts in restoring shoulder elevation in a stiff and painful shoulder patient. Phys Ther Sport 2014; 15:3-14. 


\section{SINGAPORE MEDICAL COUNCIL CATEGORY 3B CME PROGRAMME} (Code SMJ 201712A)

1. Frozen shoulder is defined as a condition of uncertain aetiology, characterised by significant restriction of both active and passive shoulder motion occurring in the absence of a known intrinsic shoulder disorder.

2. Patients with frozen shoulder typically experience severe pain, which is worse in the day and improves at night.

3. There is higher risk of primary idiopathic frozen shoulder in patients with diabetes mellitus, and it may be the first presentation of a diabetic.

4. Adhesive capsulitis can occur after shoulder injuries or immobilisation (e.g. trauma, rotator cuff tear or shoulder surgery) or with systemic diseases such as thyroid diseases and Parkinson's disease.

5. Frozen shoulder often progresses in two stages: the freezing (painful) and thawing phases.

6. In the freezing stage, which lasts about 1-2 months, there is a gradual onset of diffuse, severe shoulder pain that typically worsens at night.

7. During the thawing stage, the patient experiences a gradual return of range of motion, which takes about 5-26 months to complete.

8. Adhesive capsulitis is often self-limiting, usually resolving in 1-3 years without professional treatment.

9. Frozen shoulder is estimated to affect about $2-5$ in 100 persons among the general population, and can be significantly painful and disabling.

10. Frozen shoulder most commonly occurs in those in their sixth to eighth decades of life, and more often in women than men.

11. There are limited management modalities for frozen shoulder in the primary care setting, and these are limited to patient education of its natural history and appropriate anti-inflammatory drugs and analgesia.

12. Doctors should be encouraging and reassure patients that they will definitely regain full range of motion with adequate thawing time.

13. Physical therapy has been shown to increase pain for patients but can speed up the return of functional motion.

14. Pain is often most severe during the freezing phase, and there are no physical therapies targeted at pain relief.

15. A heat or ice pack can be applied as a modality to relieve pain before the start of physical therapy exercises.

16. Aggressive stretching beyond the pain threshold can result in faster recovery and better outcomes, particularly in the early phase of the condition.

17. Strengthening exercises are added at the frozen stage to maintain muscle strength.

18. In the thawing phase, it is crucial to get the shoulder back to normal as quickly as possible by regaining full movement and strength. Strengthening exercises are important, as the shoulder is considerably weakened after a few months of little movement.

19. Referral to a physiotherapist can be made if the patient needs more guidance or fails to improve after the recommended trial of exercises.

20. Patients with calcific tendonitis or acromial bone spur seen on shoulder radiographs need to be referred to an orthopaedics specialist for further evaluation and treatment.

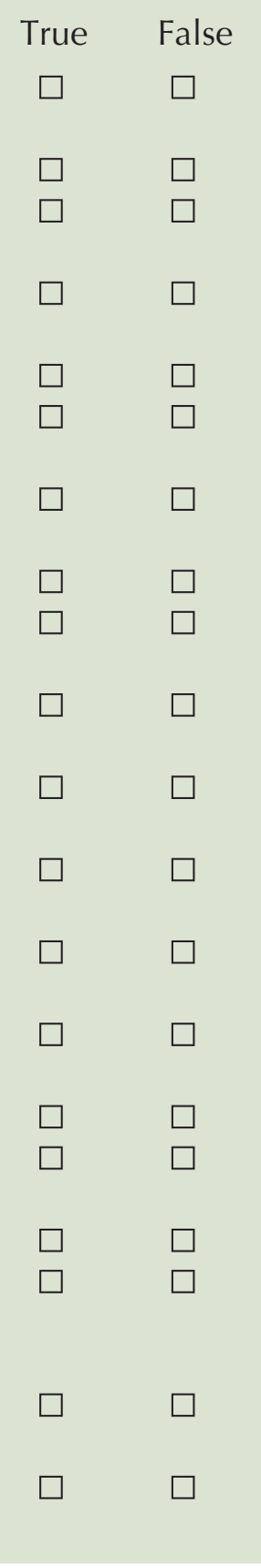

\section{Doctor's particulars:}

Name in full:

Specialty:
MCR no:

Email:

\section{SUBMISSION INSTRUCTIONS:}

Visit the SMJ website: http://www.smj.org.sg/current-issue and select the appropriate quiz. You will be redirected to the SMA login page.

For SMA member: (1) Log in with your username and password (if you do not know your password, please click on 'Forgot your password?'). (2) Select your answers for each quiz and click 'Submit'.

For non-SMA member: (1) Create an SMJ CME account, or login with your SMJ CME username and password (for returning users). (2) Make payment of SGD 21.40 (inclusive of $7 \%$ GST) via PayPal to access this month's quizzes. (3) Select your answers for each quiz and click 'Submit'.

\section{RESULTS:}

(1) Answers will be published online in the SMJ February 2018 issue. (2) The MCR numbers of successful candidates will be posted online at the SMJ website by 29 January 2018. (3) Passing mark is $60 \%$. No mark will be deducted for incorrect answers. (4) The SMJ editorial office will submit the list of successful candidates to the Singapore Medical Council. (5) One CME point is awarded for successful candidates.

Deadline for submission: (December 2017 SMJ 3B CME programme): 12 noon, 22 January 2018. 